\title{
YM155 sensitizes HeLa cells to TRAIL-mediated apoptosis via cFLIP and survivin downregulation
}

\author{
ARUN PANDIAN CHANDRASEKARAN ${ }^{1 *}$, NARESH POONDLA $^{1 *}$, NA RE KO $^{2,3}$, \\ SEUNG JUN $\mathrm{OH}^{3}$ and SURESH RAMAKRISHNA ${ }^{1,4}$
}

\begin{abstract}
${ }^{1}$ Graduate School of Biomedical Science and Engineering, Department of Biomedical Science, Hanyang University, Seoul $04763 ;{ }^{2}$ Biomedical Research Center, Asan Institute for Life Sciences; ${ }^{3}$ Department of Nuclear Medicine, Asan Medical Center, University of Ulsan College of Medicine, Seoul 05505; ${ }^{4}$ College of Medicine, Department of Genetics, Hanyang University, Seoul 04763, Republic of Korea
\end{abstract}

Received February 19, 2020; Accepted June 16, 2020

DOI: $10.3892 / 01.2020 .11933$

\begin{abstract}
Tumor necrosis factor-related apoptosis inducing ligand (TRAIL)-mediated apoptosis is a safe method for the treatment of various types of cancer. However, TRAIL therapy is less effective in certain types of cancer, including cervical cancer. To address this problem, a combinatorial approach was employed to sensitize cervical cancer at low dosages. YM155, a survivin inhibitor, was used at low dosages along with TRAIL to induce apoptosis in HeLa cells. The effects of the individual treatment with TRAIL and YM155 on apoptosis were assessed by propidium iodide assay. In addition, to validate the DNA damage exhibited by the combination treatment, the phosphorylation status of $\gamma \mathrm{H} 2 \mathrm{~A}$ histone family member $\mathrm{X}$ was investigated by immunofluorescence and western blot analysis. TRAIL or YM155 alone had no significant effect on DNA damage and apoptosis. However, the TRAIL/YM155 combination triggered a synergistic pro-apoptotic stimulus in HeLa cells. The mRNA and protein levels of CASP8- and FADD-like apoptosis regulator (cFLIP), death receptor 5 (DR5) and survivin were monitored using RT-PCR and western blot analysis, respectively. This combinatorial approach downregulated both mRNA and protein expression levels of cFLIP and survivin. Further experimental
\end{abstract}

Correspondence to: Professor Suresh Ramakrishna, Graduate School of Biomedical Science and Engineering, Department of Biomedical Science, Hanyang University, 222 Wangsimni-ro, Seongdong, Seoul 04763, Republic of Korea

E-mail: suri28@hanyang.ac.kr; suresh.ramakris@gmail.com

Professor Seung Jun Oh, Department of Nuclear Medicine, Asan Medical Center, University of Ulsan College of Medicine, 88 Olympic-ro 43-gil, Songpa, Seoul 05505, Republic of Korea E-mail: sjoh@amc.seoul.kr

*Contributed equally

Key words: tumor necrosis factor-related apoptosis inducing ligand therapy, YM155, HeLa cells, apoptosis, CASP8- and FADD-like apoptosis regulator, death receptor 5 , survivin results suggested that the combination treatment significantly reduced cell viability, invasion and migration of HeLa cells. Overall, the present findings indicated that the low dosage of YM155 sensitized HeLa cells to TRAIL-induced apoptosis via a mechanism involving downregulation of cFLIP and survivin. The results indicated the importance of combination drug treatment and reveal an effective therapeutic alternative for TRAIL therapy in human cervical cancer.

\section{Introduction}

Cervical cancer is the fourth most prevalent type of cancer in females globally and a significant cause of mortality in developing countries (1). Cervical cancer may develop due to persistent high-risk human papillomavirus (HPV) infection (2). Progress has been made in understanding the HPV genome replication during the viral life cycle; however, accurate surveillance strategies and targeted therapies are still required to eradicate this disease (3).

Tumor necrosis factor-related apoptosis inducing ligand (TRAIL) is a powerful cancer cell apoptosis-inducing factor that can induce apoptosis in a p53-independent manner (4). However, TRAIL resistance in cancer cells is a significant barrier to improve TRAIL-based clinical therapies (5). Therefore, agents are required to either improve the impact of TRAIL or overcome resistance to it $(6,7)$. Several studies have demonstrated that the cervical cancer HeLa cell line is resistant to TRAIL-induced apoptosis, and the mechanism of resistance is not fully understood $(8,9)$. Various mechanisms have been proposed for TRAIL resistance $(10,11)$. Upregulation of CASP8- and FADD-like apoptosis regulator (cFLIP) and downregulation of death receptors (DR4 and DR5) and the Bcl-2 family (Bcl-2, Bcl-xL and MCL1 apoptosis regulator, BCL2 family member) are the most commonly proposed TRAIL resistance mechanisms (12).

Survivin is an anti-apoptotic molecule that is generally overexpressed in malignant cells (13). Survivin is a member of the inhibitor of apoptosis gene family, which regulates apoptosis and the cell cycle $(13,14)$. Survivin has been reported to interact with and inhibit caspases to decrease apoptosis (15). Survivin is expressed in various types of cancer, including 
breast cancer (16), cervical cancer (17), non-small cell lung cancer (18) and osteosarcoma (19). Its upregulation is associated with survival and resistance to TRAIL-based therapy $(20,21)$.

Small molecule inhibitor YM155, a survivin suppressor, inhibits cell proliferation and mediates apoptosis in breast (22), gastric (23), liver (24), and pancreatic (25) cancer models. Other than suppressing the levels of survivin in various types of cancer, YM155 has also been reported to have strong apoptogenic properties $(26,27)$. Additionally, it has been reported that YM155 has an anticancer effect on breast (22), esophageal (28), colon (29) and bone marrow (30) cancer and sensitizes different types of cancer cells to TRAIL-mediated apoptosis (31). However, a growing body of evidence has reported that survivin has a strong inhibitory effect on TRAIL therapy (32).

The present study investigated the impact of a low dosage of YM155 on TRAIL-mediated apoptosis and molecular mechanisms underlying TRAIL sensitization in human cervical cancer cells.

\section{Materials and methods}

Cell culture. HeLa cells were procured from the Korean Cell Line Bank; Korean Cell Line Research Foundation. Cells were maintained in DMEM (PAN-Biotech GmbH) with $10 \%$ FBS (Gibco; Thermo Fisher Scientific, Inc.). A total of $100 \mu \mathrm{g} / \mathrm{ml}$ penicillin-streptomycin (HyClone; Cytiva) was added to make complete media. Cells were maintained in a $\mathrm{CO}_{2}$ cell culture incubator (Thermo Fisher Scientific, Inc.) at $37^{\circ} \mathrm{C}$ with $5 \% \mathrm{CO}_{2}$.

Reagents and antibodies. YM155 and TRAIL were purchased from Selleck Chemicals and PeproTech, Inc., respectively. Western blot and immunofluorescence analyses were performed using antibodies against cleaved-poly (ADP-ribose) polymerase (PARP; dilution, 1:1,000; cat. no. 5625S) from Cell Signaling Technology, Inc., cFLIP (dilution, 1:1,000; cat. no. 10394-1-AP) and DR5 (dilution, 1:1,000; cat. no. 15497-1-AP) from ProteinTech Group, Inc., $\gamma \mathrm{H} 2 \mathrm{~A}$ histone family member $\mathrm{X}(\gamma \mathrm{H} 2 \mathrm{AX}$; dilution, 1:1,000 for western blot and 1:100 for immunofluorescence; cat. no. 05-636) from EMD Millipore, cleaved caspase-3 (dilution, 1:100 for immunofluorescence; cat. no. 9661S) from Cell Signaling Technology, Inc., GAPDH (dilution, 1:2,000; cat. no. sc-32233) and $\beta$-tubulin (1:1,000; cat. no. sc-5274) from Santa Cruz Biotechnology, Inc., and HRP-conjugated secondary anti-mouse (1:10,000; cat. no. 31430) and anti-rabbit (1:10,000; cat. no. 31460) antibodies from Thermo Fisher Scientific, Inc., and fluorescence-conjugated secondary antibodies goat anti-mouse IgG $(\mathrm{H}+\mathrm{L})$ Alexa Fluor 488 (1:250; cat. no. A32723) and goat anti-rabbit IgG $(\mathrm{H}+\mathrm{L})$ Alexa Fluor 488 (1:250; cat. no. A27034) from Invitrogen, Thermo Fisher Scientific, Inc.

Western blotting. HeLa cells were treated with $25 \mathrm{ng} / \mathrm{ml}$ TRAIL, $25 \mathrm{nM}$ YM155 or a combination of both for $24 \mathrm{~h}$ and subjected to western blot analysis. Cells were collected after $24-\mathrm{h}$ incubation at $37^{\circ} \mathrm{C}$ and $5 \% \mathrm{CO}_{2}$ and lysed with a protein extraction buffer $(20 \mathrm{mM}$ Tris- $\mathrm{HCl} \mathrm{pH} 7.5,150 \mathrm{mM}$ $\mathrm{NaCl}, 1 \mathrm{mM} \mathrm{Na}{ }_{2}$ EDTA, $1 \mathrm{mM}$ EGTA, $1 \% \mathrm{NP}-40,1 \%$ sodium deoxycholate, $2.5 \mathrm{mM}$ sodium pyrophosphate, $1 \mathrm{mM}$ b-glycerophosphate, $1 \mathrm{mM} \mathrm{Na} \mathrm{VO}_{4}, 1 \mu \mathrm{g} / \mathrm{ml}$ leupeptin) with a PMSF protease inhibitor (Cell Signaling Technology, Inc.). The protein concentration was determined by Bradford assay (Bio-Rad Laboratories, Inc.). Then, $50 \mu \mathrm{g}$ protein was loaded on 8 or $12 \%$ SDS-PAGE and transferred to PVDF membrane (EMD Millipore) activated by methanol. Following transfer, non-specific binding was blocked with $5 \%$ skim milk and incubated at room temperature for $1 \mathrm{~h}$. The membranes were probed with primary antibodies and incubated at $4^{\circ} \mathrm{C}$ for overnight. Subsequently, the membranes were incubated with a HRP-conjugated secondary antibody for $1 \mathrm{~h}$ at room temperature and washed thrice for $5 \mathrm{~min}$ with TBS-Tween $20(0.05 \%)$ to remove unbound probes. The membranes were subjected to chemiluminescence-based detection (Pierce ECL Plus; Thermo Fisher Scientific Inc.). Imaging was performed using a ChemiDoc system with Image Lab software version 5.2 (Bio-Rad Laboratories, Inc.).

Flow cytometry. Apoptosis was assessed using propidium iodide (PI) staining kit (BD Biosciences) according to the manufacturer's protocol. Briefly, HeLa cells were seeded at a density of $2.5 \times 10^{5}$ per well and treated with $25 \mathrm{ng} / \mathrm{ml}$ TRAIL and $25 \mathrm{nM}$ YM155 for $24 \mathrm{~h}$. Subsequently, 5x10 4 cells were collected and washed with ice-cold PBS twice in the presence of $10 \% \mathrm{FBS}$, and $70 \%$ ethanol was added into the cell suspensions. A total of $2 \mathrm{mg} / \mathrm{ml}$ RNaseA was added and incubated for $15 \mathrm{~min}$ at $4^{\circ} \mathrm{C}$. Finally, cells were stained with $10 \mu \mathrm{l} \mathrm{PI}$ $(50 \mathrm{mg} / \mathrm{ml})$ at room temperature for $10 \mathrm{~min}$. DNA content was measured within $1 \mathrm{~h}$ using flow cytometry (FACS CANTO II; BD Biosciences). Data were analyzed using FACSDiva software (version 8; BD Biosciences).

Immunofluorescence. Immunofluorescence was used to assess nuclear morphology and DNA damage by $\gamma \mathrm{H} 2 \mathrm{AX}$ foci formation and cleaved caspase- 3 activation assays. A total of $2 \times 10^{4}$ HeLa cells were seeded into a 4-well dish containing cover slips and incubated overnight. Subsequently, HeLa cells were treated with $25 \mathrm{ng} / \mathrm{ml}$ TRAIL and/or $25 \mathrm{nM}$ YM155 and incubated for $24 \mathrm{~h}$. The reaction was immediately stopped and cells were fixed with $4 \%$ paraformaldehyde at room temperature (Wako Chemicals USA, Inc.) for $20 \mathrm{~min}$. Fixed cells were washed using 0.03\% Triton-X 100 (Sigma-Aldrich; Merck $\mathrm{KGaA}$ ) three times. To eliminate non-specific binding, 5\% BSA (Bovogen Biologicals Pty Ltd.) in 1X PBS was used as a blocking reagent. After $1 \mathrm{~h}$ of blocking at room temperature, primary antibody was added, followed by incubation at $4^{\circ} \mathrm{C}$ overnight. The next day, cells were washed using PBS and incubated with relevant Alexa Fluor 48-8 and 594-conjugated secondary antibodies at room temperature for $1 \mathrm{~h}$. DAPI ( $1 \mu \mathrm{g} / \mathrm{ml}$; Invitrogen; Thermo Fisher Scientific, Inc.) was added to the cells and incubated at room temperature for $15 \mathrm{~min}$ to stain the nuclei, and cells were mounted on glass slides. Cells were imaged at $\mathrm{x} 40$ magnification using a confocal microscope (Leica TCS SP5; Leica Microsystems GmbH).

Reverse transcription-quantitative $(R T-q) P C R$. HeLa cells were treated with $25 \mathrm{ng} / \mathrm{ml}$ TRAIL and/or $25 \mathrm{nM}$ YM155 for $24 \mathrm{~h}$ and harvested for RNA extraction. TRIzol ${ }^{\circledR}$ reagent (Favorgen Biotech Corporation) was used to extract the RNA. A total of $40 \mathrm{ml}$ RNase-free water was added to the extracted 
vial to reconstitute the RNA. Total RNA concentration was quantified using a Nanodrop (Thermo Fisher Scientific, Inc.). The SuperScript III First-Strand Synthesis System (Thermo Fisher Scientific, Inc.) was used to synthesize the cDNA according to the manufacturer's protocol. Briefly, $1 \mu \mathrm{g}$ of total RNA was reverse transcribed using the SuperScript III kit with 25 pmol oligo-dT primer and 50 pmol random hexamer. Then, the cDNA was diluted at 1:10 with dilution buffer provided by the manufacturer. QPCR was performed using a real-time PCR system (Thermo Fisher Scientific, Inc.) and Fast SYBR ${ }^{\circledR}$ Green Master Mix (Thermo Fisher Scientific, Inc.) with the following primers: DR5 forward, 5'-CCCAACAAGACCTAG CTCCC-3' and reverse, 5'-GACCTCCTTTTCTGCTTGCG-3'; cFLIP forward, 5'-GCCGAGGCAAGATAAGCAAG-3' and reverse, 5'-AGTCTGTTCAAGGAGCAGGG-3'; survivin forward, 5'-AGAACTGGCCCTTCTTGGAGG-3' and reverse, 5'-CTTTTTATGTTCCTCTATGGGGTC-3'; and GAPDH forward, 5'-CTGACTTCAACAGCGACACC-3' and reverse, 5'-TAGCCAAATTCGTTGTCATACC-3'. The relative quantification of gene expression was determined using the $2^{-\Delta \Delta \mathrm{Cq}}$ method (33). The thermocycling conditions were as follows: Pre-incubation at $95^{\circ} \mathrm{C}$ for $3 \mathrm{~min}$, followed by 45 cycles of $95^{\circ} \mathrm{C}$ for $15 \mathrm{sec}$ and $60^{\circ} \mathrm{C}$ for $60 \mathrm{sec}$. The final amplification cycle was followed by a melt curve analysis for the specificity of the RT-qPCR.

Cell viability assay. The cytotoxicity of TRAIL and YM155 was assessed using a Cell Counting Kit-8 (CCK-8; Dojindo Molecular Technologies, Inc.). Following drug treatment, $10 \mu \mathrm{l}$ CCK- 8 reagent was added, and the mixture was incubated at $37^{\circ} \mathrm{C}$ for $2 \mathrm{~h}$ according to the manufacturer's instructions. Subsequently, absorbance was measured at $540 \mathrm{~nm}$ using a microtiter plate reader (Bio-Rad Laboratories, Inc.).

Matrigel invasion assay. HeLa cells were seeded, and cell invasion was evaluated using $0.8-\mu \mathrm{m}$ Transwell chambers coated with Matrigel at $37^{\circ} \mathrm{C}$ for $1 \mathrm{~h}$ (Corning Inc.) according to the manufacturer's protocol. In brief, HeLa cells were suspended at a density of $2.5 \times 10^{4}$ cells in $500 \mu 1$ serum-free DMEM and placed in the upper chamber. Subsequently, $700 \mu \mathrm{l}$ complete DMEM was added to the lower chamber, followed by incubation at $37^{\circ} \mathrm{C}$ for $24 \mathrm{~h}$. Cells on the surface of the insert were removed, and the lower surface was fixed with ice-cold methanol at room temperature for $15 \mathrm{~min}$. After fixing, cells were stained with crystal violet $(0.1 \%$, diluted in methanol) for $5 \mathrm{~min}$ at room temperature. Cells were counted using bright field microscopy and compared among the DMSO, YM155, TRAIL and combination groups. The numbers of invaded cells were represented graphically.

In vitro scratch assay. An in vitro scratch assay was performed to assess the migratory activity of HeLa cells treated with $25 \mathrm{ng} / \mathrm{ml}$ TRAIL and/or $25 \mathrm{nM}$ YM155. After 24-h treatment, the cells were harvested and re-seeded at $90 \%$ confluency and incubated at $37^{\circ} \mathrm{C}$ overnight. Using a sterile pipette tip, scratches were made in the monolayers of HeLa cells. The scratched monolayer was washed with PBS and incubated at $37^{\circ} \mathrm{C}$ with serum-free $1 \mathrm{X}$ DMEM. The wounded region was captured under a light microscope (IX71; Olympus Corporation) at $0,24,48$ and $72 \mathrm{~h}$, and Image $1.51 \mathrm{j} 8$ software
(National Institutes of Health) was used to calculate the percentage of wound closure as previously described (34). Data were obtained from three independent experiments.

Soft agar assay. DMEM (1X) complete medium and 1\% agarose were mixed at an equal ratio of $1: 1(\mathrm{v} / \mathrm{v})$ and plated onto 35-mm dishes. The next day, cells were seeded at a density of $1 \times 10^{4}$ per well and suspended in $0.7 \%$ agarose $/ 1 \mathrm{X}$ DMEM mixture. Subsequently, 1\% DMSO, 5 nM YM155, $5 \mathrm{ng} / \mathrm{ml}$ TRAIL and YM155/TRAIL combination were added to DMEM. Medium containing the aforementioned drug concentrations was added every other day for 14 days. Crystal violet $(0.01 \%$ diluted in $20 \%$ methanol) was added at room temperature for $5 \mathrm{~min}$ to stain anchorage-independent colonies. Finally, cells were observed under a light microscope at $\mathrm{x} 4$ magnification.

Statistical analysis. Statistical analysis was performed using GraphPad Prism 8 (GraphPad Software, Inc.) and data are presented as the mean \pm standard deviation of three independent experiments. Data were analyzed by one-way ANOVA. Multiple comparisons among the groups were performed by Tukey's post hoc test. For in vitro scratch assay, two-way ANOVA followed by Tukey's post hoc test was performed. $\mathrm{P}<0.05$ was considered to indicate a statistically significant difference.

\section{Results}

YM155 sensitizes HeLa cells to TRAIL-mediated apoptosis. First, HeLa cells were treated with $1 \%$ DMSO, $25 \mathrm{ng} / \mathrm{ml}$ TRAIL or $25 \mathrm{nM}$ YM155 for $24 \mathrm{~h}$. PI staining was used to analyze apoptotic cells by flow cytometry (Fig. 1A and B). TRAIL or YM155 alone did not induce cell death in HeLa cells (Fig. 1A and B), whereas the combination of TRAIL and YM155 significantly increased the sub- $G_{1}$ population compared with the DMSO control group in HeLa cells (Fig. 1C). To further validate the combinatorial effect of TRAIL-YM155, western blotting was performed to assess cleaved-PARP levels. Consistent with the sub-G1 population experimental results, combination treatment induced greater cleaved-PARP expression than individual treatment (Fig. 1D). Overall, YM155 enriched TRAIL-mediated apoptosis via an extrinsic signaling pathway in human cervical cancer cells.

Combination of TRAIL and YM155 induces DNA damage toxicity in HeLa cells. In order to investigate whether combination treatment of TRAIL and YM155 lead to DNA damage, cells were treated with $25 \mathrm{ng} / \mathrm{ml}$ TRAIL or $25 \mathrm{nM}$ YM155 alone and in combination. Bright-field microscopy images revealed that cells in the combination treatment group exhibited apoptotic morphology, whereas cells in the single agent treatment groups did not (Fig. 2A). Subsequently, the shape of the nucleus of HeLa cells was assessed by staining with DAPI. As presented in Fig. 2B, chromatin condensation was observed following combination treatment but not when cells were treated with TRAIL or YM155 alone. To further confirm that combination treatment induces DNA damage in HeLa cells, $\gamma \mathrm{H} 2 \mathrm{AX}$ foci formation was assessed using immunofluorescence. As presented in Fig. 2C, robust $\mathrm{H} 2 \mathrm{AX}$ phosphorylation 
A

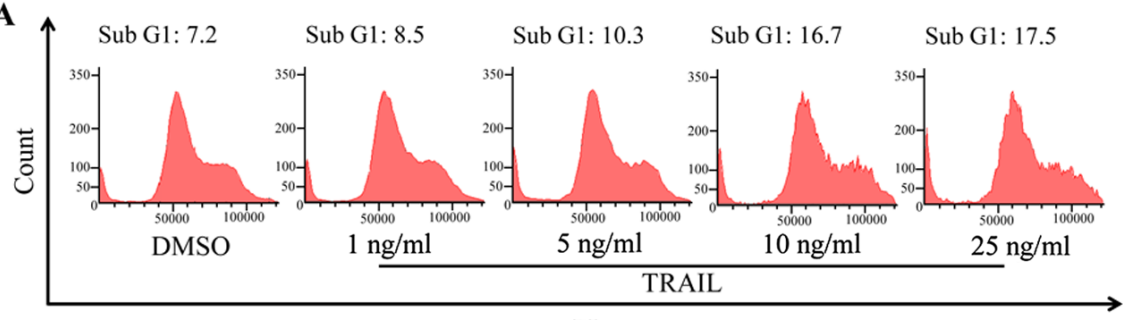

PI

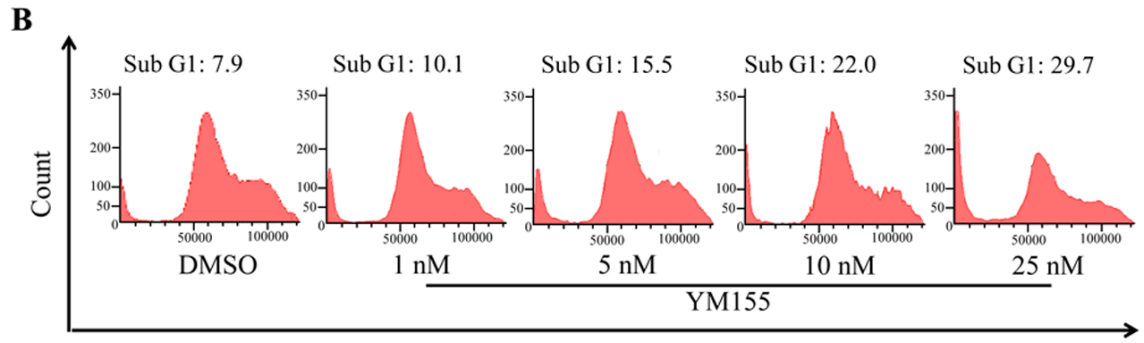

PI

C

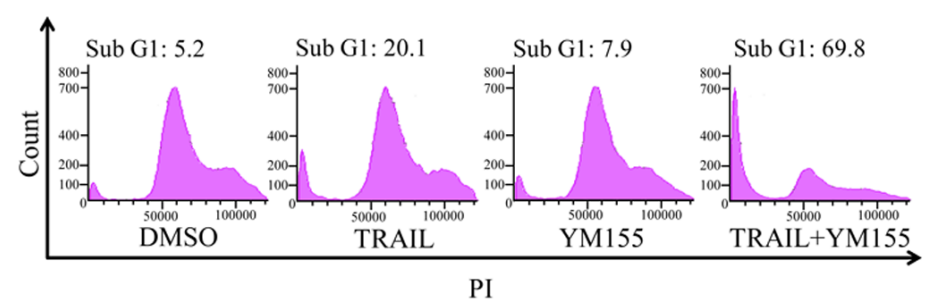

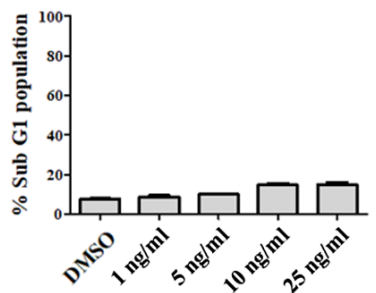

TRAIL

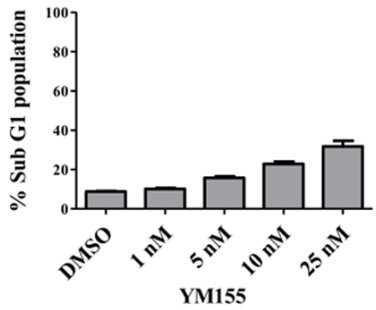

D
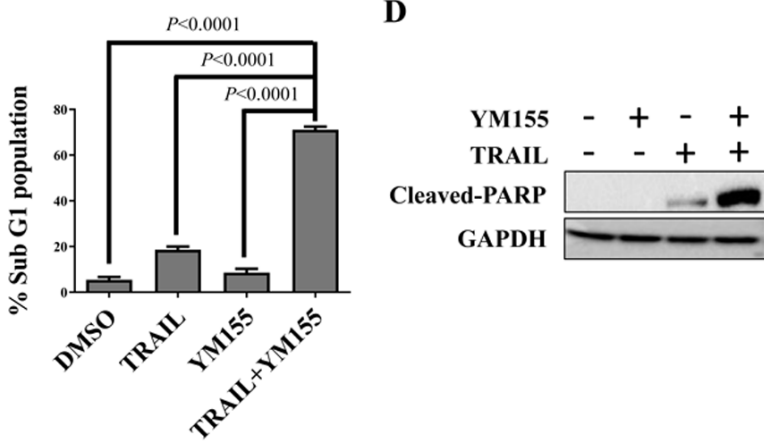

Figure 1. YM155 sensitizes HeLa cells to TRAIL-induced apoptosis. (A) HeLa cells were treated with indicated concentrations of TRAIL for $24 \mathrm{~h}$ and DNA content was measured by flow cytometry using PI staining. (B) HeLa cells were treated with indicated concentrations of YM155 for $24 \mathrm{~h}$ and PI staining was used for flow cytometry. (C) HeLa cells were treated with $25 \mathrm{ng} / \mathrm{ml}$ TRAIL and $25 \mathrm{nM}$ YM155 for $24 \mathrm{~h}$ and subjected to PI staining and flow cytometry to assess the apoptotic population. Data are presented as the mean and standard deviation of three independent experiments. One-way ANOVA followed by Tukey's post hoc test was used and P-values are indicated. (D) HeLa cells were treated with $25 \mathrm{ng} / \mathrm{ml}$ TRAIL and $25 \mathrm{nM}$ YM155 and subjected to western blotting with cleaved-PARP antibody. GAPDH was used as the loading control. PARP, poly (ADP-ribose) polymerase; PI, propidium iodide; TRAIL, tumor necrosis factor-related apoptosis inducing ligand.

was observed in HeLa cells treated with the combination of TRAIL and YM155 compared with in the single agent treatment and DMSO control groups. Consistent with the aforementioned results, combination treatment of TRAIL and YM155 resulted in higher protein expression levels of $\gamma \mathrm{H} 2 \mathrm{AX}$ than individual treatment (Fig. 2D). Overall, the combination of TRAIL and YM155 induced DNA damage in HeLa cells but individual treatment did not.

YM155 increases TRAIL-induced apoptosis via downregulation of cFLIP and survivin levels. In order to determine the mechanisms underlying YM155-mediated TRAIL sensitivity in HeLa cells, apoptosis-associated proteins, including DR5 (pro-apoptotic), cFLIP (anti-apoptotic) and survivin (anti-apoptotic) were examined in the present study. HeLa cells were treated with $1 \%$ DMSO, $25 \mathrm{ng} / \mathrm{ml}$ TRAIL or $25 \mathrm{nM}$ YM155 alone and in combination for $24 \mathrm{~h}$ and then subjected to RT-qPCR analysis. As presented in Fig. 3, HeLa cells treated with both TRAIL and YM155 exhibited downregulation of cFLIP and survivin at the mRNA and protein levels (Fig. 3A, C and D). DR5, a pro-apoptotic protein involved in TRAIL sensitivity (35), exhibited no changes following combination treatment (Fig. 3B and D). Notably, treatment with TRAIL alone induced a significant increase in the mRNA levels of DR5 (Fig. 3B). Similarly, the protein level of DR5 was also upregulated by TRAIL treatment (Fig. 3D). This suggests that DR5 upregulation was specific to TRAIL treatment alone and not in combination. The aforementioned data indicate that downregulation of cFLIP and survivin serves a major role in combination treatment of YM155 and TRAIL-mediated apoptosis.

Combination treatment decreases cancer progression in vitro. The effect of TRAIL and YM155 combination treatment in HeLa cells was next assessed using a cell viability assay. As presented in Fig. 4A, combination treatment of TRAIL and YM155 significantly decreased the viability of HeLa cells (2.08-fold) compared with the DMSO control. To test the hypothesis that the combination of TRAIL and YM155 decreases cancer progression, the effect of the combination treatment on HeLa cell migration and invasion was assessed using an in vitro scratch assay and Matrigel-coated chamber invasion assay, respectively. HeLa cells treated with both 

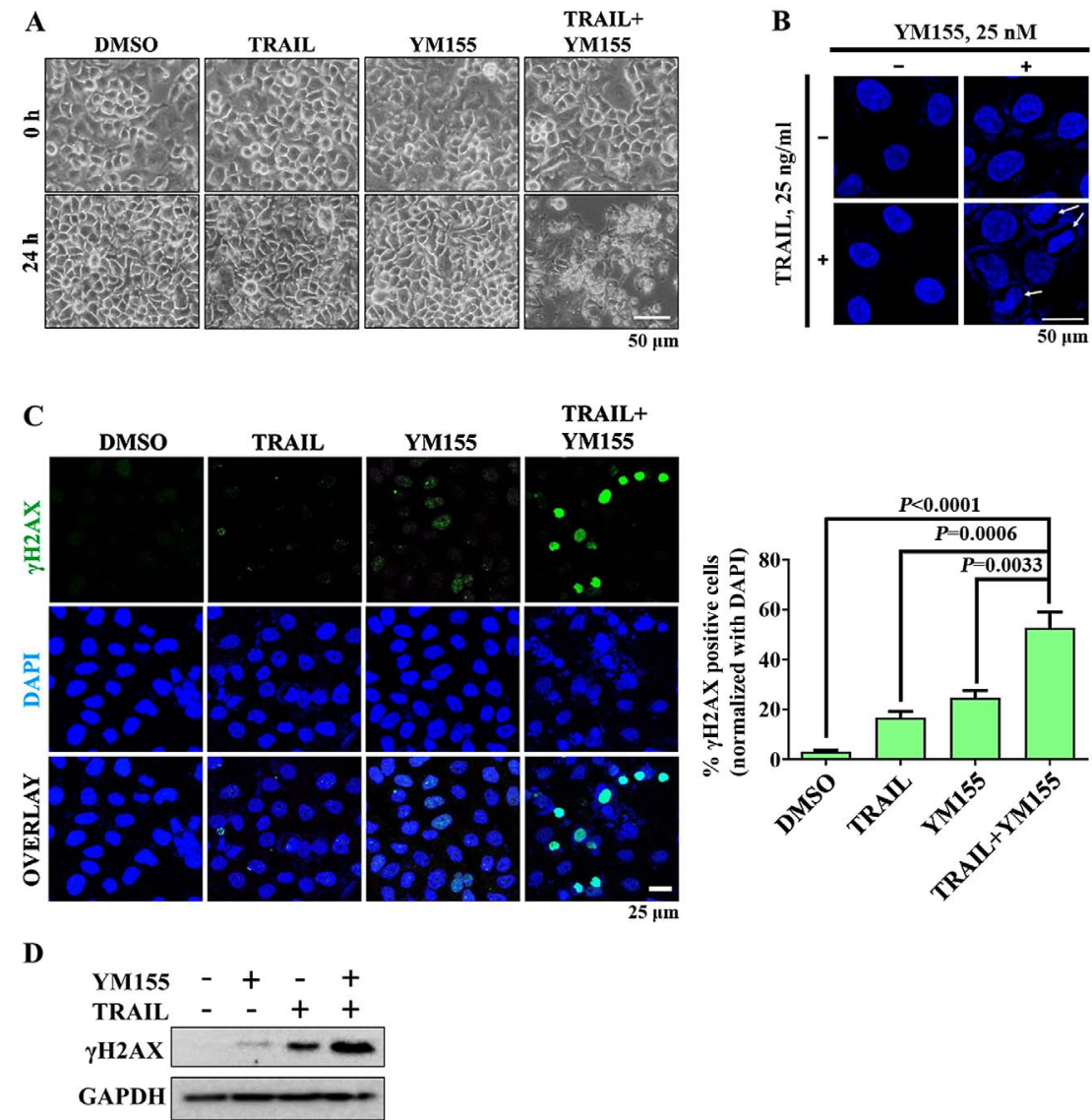

Figure 2. Effect of combination treatment on DNA damage in HeLa cells. HeLa cells were treated with $25 \mathrm{ng} / \mathrm{ml}$ TRAIL and $25 \mathrm{nM}$ YM155 for $24 \mathrm{~h}$ and subjected to subsequent analysis. (A) Morphological alterations in HeLa cells were observed using bright-field microscopy. Assays were performed in triplicate. Scale bar, $50 \mu \mathrm{M}$. (B) Immunofluorescence experiments were performed to assess nucleus morphology by DAPI staining (blue). Arrows indicate nucleus condensation. Assays were performed in triplicate. Scale bar, $50 \mu \mathrm{m}$. (C) DNA double strand breaks in HeLa cells were estimated using a $\gamma \mathrm{H} 2 \mathrm{AX}$ foci formation assay. Assays were performed in triplicate. Green, $\gamma \mathrm{H} 2 \mathrm{AX}$; blue, nucleus stained with DAPI. Magnification, $\mathrm{x} 20$. Scale bar, $25 \mu \mathrm{m}$. The right panel shows the calculated data, presented as the $\gamma \mathrm{H} 2 \mathrm{AX}$-positive cells. Data are presented as the mean and standard deviation of three independent experiments. One-way ANOVA followed by Tukey's post hoc test was used and P-values are indicated. (D) Western blot analysis was performed to assess DNA damage using an endogenous $\gamma \mathrm{H} 2 \mathrm{AX}$ antibody. GAPDH was used as the loading control. $\gamma \mathrm{H} 2 \mathrm{AX}, \gamma \mathrm{H} 2 \mathrm{~A}$ histone family member X; TRAIL, tumor necrosis factor-related apoptosis inducing ligand.

TRAIL and YM155 exhibited a significant decrease in invasive capability compared with the DMSO control and single agent treatment groups (Fig. 4B). Consistently, combination treatment also resulted in a delayed wound closure rate compared with the DMSO control and single agent treatment groups (Fig. 4C). It has been reported that caspase- 3 is a cysteine-aspartic acid protease that will be cleaved by TRAIL and executes apoptosis in cancer cells $(36,37)$. Therefore, the present study monitored the levels of cleaved caspase- 3 in HeLa cells. To achieve this, HeLa cells were treated with the $25 \mathrm{ng} / \mathrm{ml}$ TRAIL or $25 \mathrm{nM}$ YM155 alone or in combination for $24 \mathrm{~h}$. Subsequently, cleaved caspase-3 levels in samples were evaluated by immunofluorescence. It was observed that the combination treatment of TRAIL and YM155 significantly increased the cleaved caspase-3 levels compared with DMSO and TRAIL or YM155 alone treated samples (Fig. 4D). Subsequently, cell proliferation was assessed using an anchorage-independent colony formation assay. HeLa cells were selected with the combination of $5 \mathrm{ng} / \mathrm{ml}$ of TRAIL and $5 \mathrm{nM}$ of YM155 or individual treatment, and colony formation was analyzed. The number of colonies that appeared in cells treated with both TRAIL and YM155 was significantly lower compared with the DMSO control and single agent treatment groups (Fig. 4E). Overall, the results of the present study suggest that combination treatment of TRAIL and YM155 decreased the viability, invasion and migration of HeLa cells. The synergistic behavior of TRAIL/YM155 combination further induced DNA damage and apoptosis and may be an effective strategy to treat human cervical cancer.

\section{Discussion}

Despite the use of aggressive and toxic treatments, patients with advanced stage cervical cancer have an unacceptably high mortality rate; an estimated 13,800 new cervical cancer will be diagnosed and 4,290 deaths will occur in the United States in 2020 (38). Epidemiological, clinical and cellular studies have reported that persistent HPV infections are involved in the development of cervical cancer (38), although cervical cancer can also develop without HPV infection. The poor survival percentage demands research into more effective novel treatment approaches. In the present study, the sensitivity of TRAIL improved with the addition of YM155 in the treatment of human cervical cancer cells. The therapeutic potential 
A

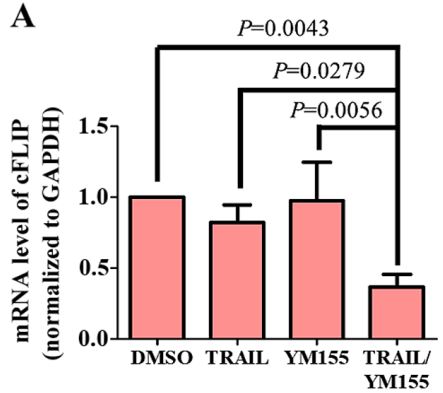

D

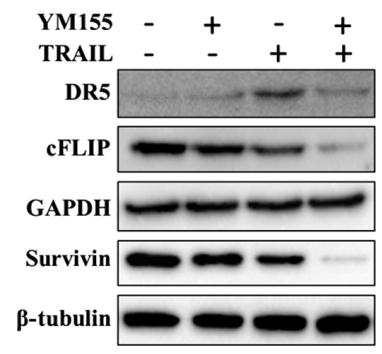

B
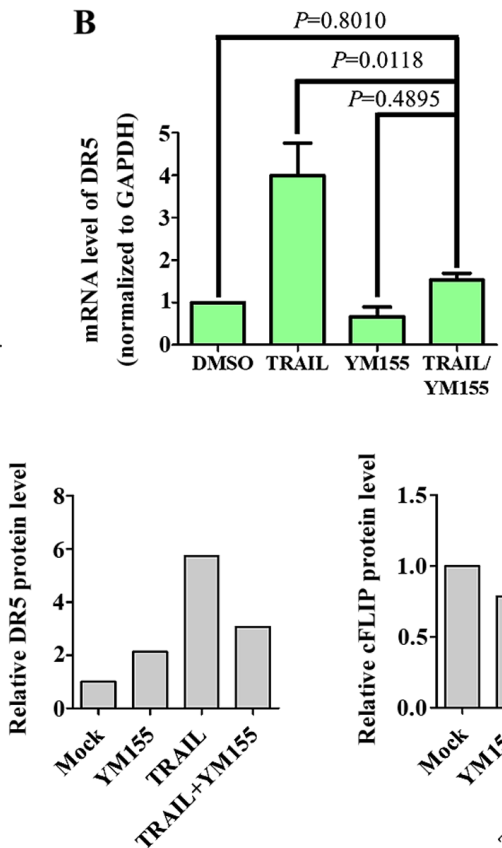

C
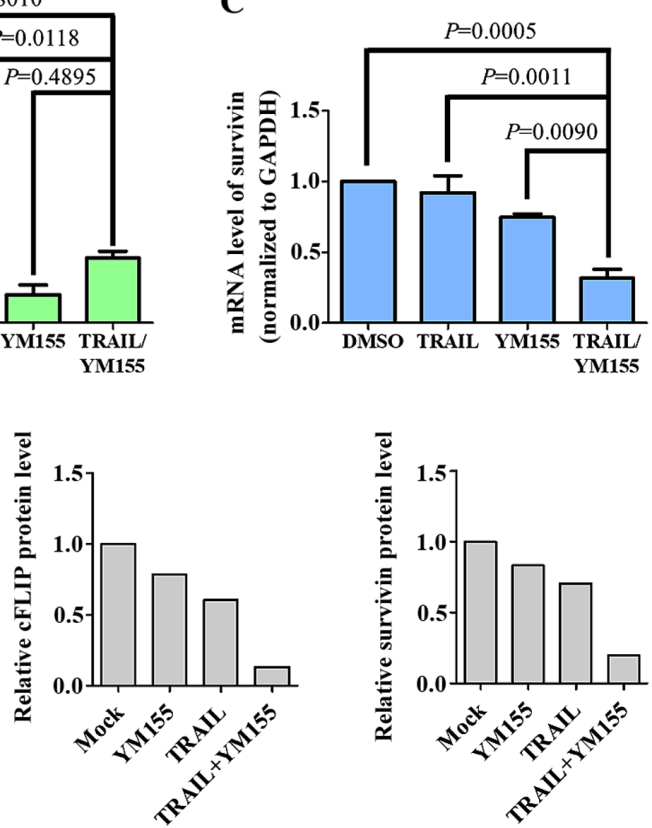

Figure 3. Combination treatment downregulates mRNA and protein levels of cFLIP and survivin. Reverse transcription-quantitative PCR was used to assess the mRNA expression levels of (A) cFLIP, (B) DR5 and (C) survivin following treatment with $25 \mathrm{ng} / \mathrm{ml}$ TRAIL and $25 \mathrm{nM}$ YM155 for $24 \mathrm{~h}$. Data are presented as the mean and standard deviation of three independent experiments. One-way ANOVA followed by Tukey's post hoc test was used, and P-values are indicated. (D) Western blotting was performed to assess protein expression levels of cFLIP, DR5 and survivin after treatment with $25 \mathrm{ng} / \mathrm{ml}$ TRAIL and $25 \mathrm{nM}$ YM155 for $24 \mathrm{~h}$. GAPDH and $\beta$-tubulin were used as the loading controls. cFLIP, CASP8 and FADD like apoptosis regulator; DR5, death receptor 5; TRAIL, tumor necrosis factor-related apoptosis inducing ligand.

of TRAIL and YM155 combination treatment was analyzed in HeLa cells. Previous research has demonstrated that HeLa cells are less sensitive to TRAIL-induced apoptosis $(39,40)$. To sensitize the HeLa cells to TRAIL-mediated apoptosis, YM155 was used as a combinatorial drug partner. YM155 has been reported as a survivin inhibitor developed for cancer treatment, and its effects have been demonstrated in multiple preclinical studies and phase I/II clinical trials (41-44).

Several reports have suggested that YM155 sensitizes cells to TRAIL-induced apoptosis in human renal carcinoma Caki cells (31), triple negative breast cancer (45) and a number of other types of cancer. However, to the best of our knowledge, there are currently no data on the combination of TRAIL and YM155 in human cervical cancer. Therefore, the effect of YM155 on the induction of TRAIL-mediated apoptosis in HeLa cells was assessed in the present study. It was revealed that HeLa cells were sensitized by the addition of a low concentration of YM155, but not in individually treated groups. Previous studies have suggested that YM155 induces DNA damage in several types of cancer $(46,47)$. Therefore, phosphorylation of H2AX, which causes double strand breaks, was assessed by immunofluorescence and western blotting assays. YM155-treated cells expressed $\gamma \mathrm{H} 2 \mathrm{AX}$. Notably, treatment with TRAIL alone did not induce DNA damage, whereas the combination treatment of TRAIL and YM155 was associated with marked expression of $\gamma \mathrm{H} 2 \mathrm{AX}$ in HeLa cells and eventually led to apoptosis. A previous report has suggested that the combination of YM155 and TRAIL in $\mathrm{SiHa}$ cells induced a $48 \%$ higher apoptotic rate compared with that of the DMSO group (48), whereas the present combinatorial approach demonstrated an $\sim 71 \%$ increase in apoptosis relative to that of the DMSO group by activating cleaved caspase- 3 in HeLa cells. The main difference is that the cells were first treated with YM155 alone for $24 \mathrm{~h}$ and then TRAIL treatment was applied for another $15 \mathrm{~h}$ in the previous study whereas the present study induced apoptosis via synergistic action of YM155 and TRAIL together in cervical cancer cells. This explains the importance of the synergistic behavior of YM155/TRAIL in a cellular environment to hinder the progress of cervical cancer growth. It is important to note that the use of antibiotics in drug response studies can alter gene expression (49). Both genetic and phenotypical characterizations of YM155 and TRAIL have been studied extensively (50-53). Throughout the experiments in the present study, both the control and experimental groups received equal amounts of antibiotics, and thus, their effects on the results were negligible.

Previous data revealed that DR5 is the major determinant of TRAIL-induced apoptosis $(54,55)$, and cFLIP and survivin confer resistance to TRAIL therapy for different cancer types $(56,57)$. Several reports have demonstrated that DR5 serves a greater role in apoptosis compared with that of DR4 $(58,59)$. DR5 activates the extrinsic apoptotic signaling pathway by binding of the death ligand (TRAIL) $(60,61)$. However, the action of TRAIL-mediated apoptosis is mainly associated with Fas-associated via death domain (FADD) recruitment to the DR5/TRAIL complex. cFLIP inhibits the action of FADD and prevents it from binding to the DR5/TRAIL complex $(62,63)$. High cFLIP expression in human cervical cancer confers resistance to TRAIL therapy (64). Additionally, it has been noted that DR4 serves an antagonistic role to DR5 in TRAIL-mediated apoptosis (59). Furthermore, DR4 is responsible for the sensitization of cancer cells during the combination treatment involving irradiation (39). Therefore, 
A

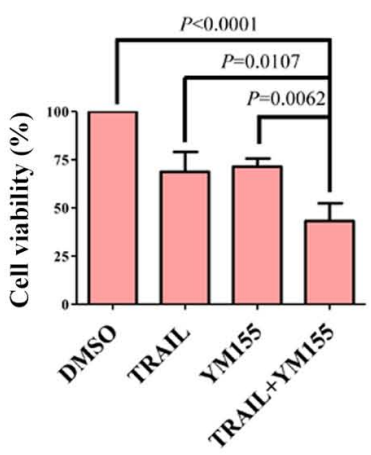

B

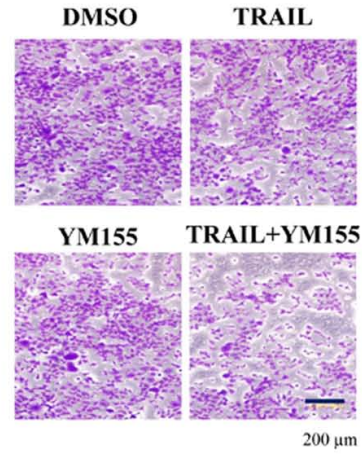

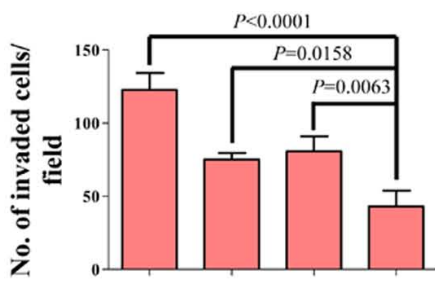

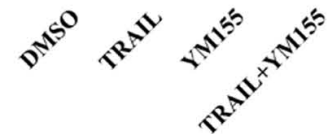

C
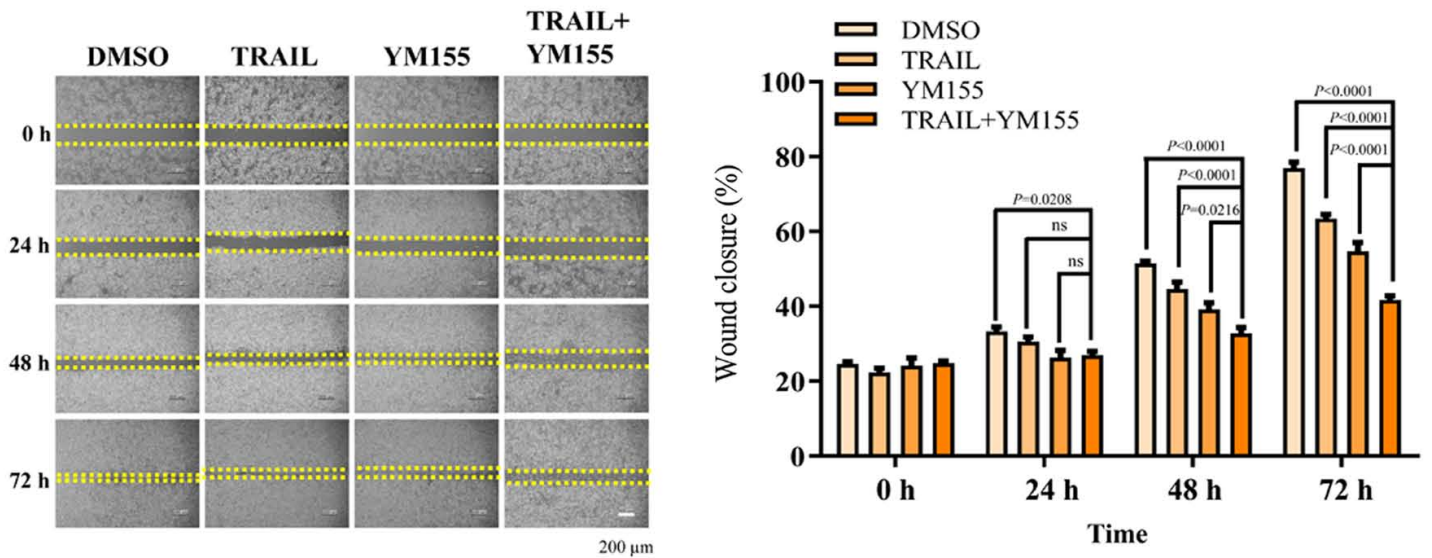

D

DMSO

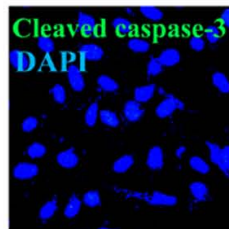

YM155

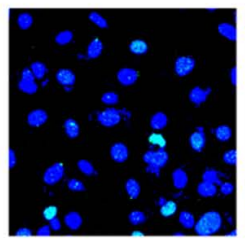

TRAIL

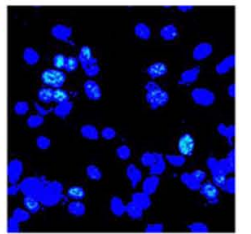

TRAIL+YM155

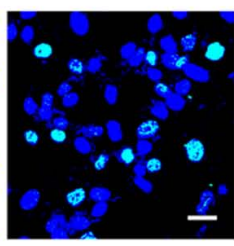

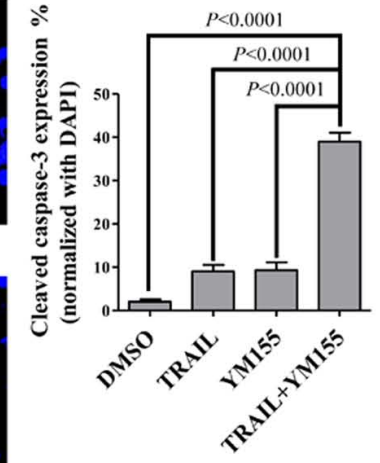

E
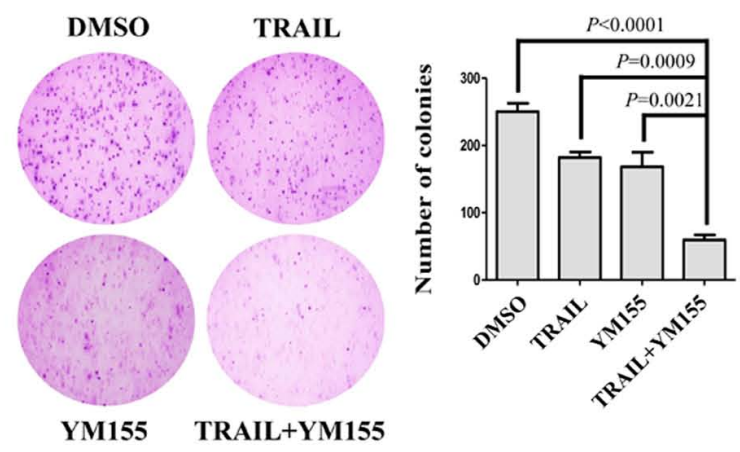

Figure 4. Effect of combination treatment on cell viability, cellular invasion and migration of HeLa cells. (A) HeLa cells were treated with $25 \mathrm{ng} / \mathrm{ml} \mathrm{TRAIL}$ and $25 \mathrm{nM}$ YM155 for $24 \mathrm{~h}$. Cell Counting Kit-8 reagent was added to the treated cells to assess cell viability. (B) Matrigel cell invasion assay in HeLa cells Cells were treated with $25 \mathrm{ng} / \mathrm{ml}$ TRAIL and $25 \mathrm{nM}$ YM155 for $24 \mathrm{~h}$. Cells were seeded in the upper chamber of the plate. After $24 \mathrm{~h}$ of incubation, cells on the bottom of the chamber membrane were fixed, stained and invasive cells were counted for graphical representation. Scale bar, $200 \mu \mathrm{m}$. (C) HeLa cells were treated with $25 \mathrm{ng} / \mathrm{ml}$ TRAIL and $25 \mathrm{nM} \mathrm{YM} 155$ for $24 \mathrm{~h}$ and assessed for migratory potential using a wound healing assay. Images were captured at 0,24, 48 and $72 \mathrm{~h}$. Scale bar, $200 \mu \mathrm{m}$. Right panel indicates the percentage of wound closure. Data are presented as the mean and standard deviation of three independent experiments. Two-way ANOVA was used and P-values are as indicated. (D) HeLa cells were treated with either TRAIL or YM155 or the combination at $25 \mathrm{ng} / \mathrm{ml}$ or $25 \mathrm{nM}$, respectively, for $24 \mathrm{~h}$. An immunofluorescence assay was performed to monitor the activation of cleaved caspase-3 (green). Nuclei were stained with DAPI (blue). Scale bar, $50 \mu \mathrm{m}$. Right panel is the quantified data presented as the percentage of cleaved caspase-3 expression. (E) HeLa cells were selected with $5 \mathrm{ng} / \mathrm{ml}$ of TRAIL and/or $5 \mathrm{nM}$ of YM155. After 14 days of selection with $5 \mathrm{ng} / \mathrm{ml}$ TRAIL and $5 \mathrm{nM}$ YM155, colonies were stained with $0.01 \%$ crystal violet, and images were captured at $\mathrm{x} 4$ magnification. The assay was performed in triplicate. The right panel is the quantified data of the soft agar assay presented as colony numbers. Data are presented as the mean and standard deviation of three independent experiments. One-way ANOVA followed by Tukey's post hoc test was used, and P-values are as indicated. TRAIL, tumor necrosis factor-related apoptosis inducing ligand.

regulating cFLIP is more crucial than the other genes involved in DR5/TRAIL-mediated apoptotic signaling pathway. However, elucidating the role of DR4 in TRAIL-mediated apoptosis is essential for future investigations. In our previous study, cFLIP was successfully downregulated in HeLa cells using the CRISPR-Cas9 system and its effectiveness in
TRAIL-mediated apoptosis was examined (8). On the other hand, consistent with our previous study (8), the mRNA and protein expression levels of cFLIP were decreased when HeLa cells were treated with TRAIL and YM155 together. However, this combinatorial approach did not alter endogenous DR5 expression. 
Both the mRNA and protein expression levels of survivin were not significantly decreased when the low dose of YM155 (25 nM) alone was applied. Similarly, a low concentration of YM155 (20 nM) did not exhibit any inhibitory effect on survivin expression in human renal cell carcinoma cell lines treated for $48 \mathrm{~h}$; however, high concentrations of YM155 $(>40 \mathrm{nM})$ decrease survivin protein levels in renal cell carcinoma cells (27). It was hypothesized that a low concentration of YM155 does not block the transcription of baculoviral IAP repeat containing 5 (BIRC5), a gene that encodes the survivin protein, and thus it has no inhibitory effect on survivin in these cell lines (27). However, further research is required at the transcriptional level to elucidate the interaction of the low dosage of YM155 and the BIRC5 gene. In the present study, the low dosage of YM155 sensitized HeLa cells to TRAIL-mediated apoptosis and decreased the mRNA and protein levels of survivin. Therefore, the combination therapy holds promise as a method to overcome the problem of side effects due to high doses and could be safe for use in patients. However, further investigations are required to validate the combination treatment in different human cervical cancer cell lines and its potential outcome in mouse xenograft models.

As available treatments have limited efficacy in human cervical cancer (64), the identification of novel therapeutic approaches to enhance patient outcomes is urgently required. The present study suggests combination treatment using YM155 and TRAIL as a therapeutic approach. Specifically, YM155 enhanced TRAIL-mediated apoptosis in HeLa cells. The results demonstrated that YM155 sensitizes human cervical cancer cells to TRAIL-induced cell death by activating the intrinsic pathway of apoptosis, and YM155/TRAIL combination downregulated anti-apoptotic proteins, such as cFLIP and survivin, in HeLa cells.

\section{Acknowledgements}

The authors would like to thank Dr Bharathi Suresh (Hanyang University, Seoul, Republic of Korea) for her assistance with statistical analysis.

\section{Funding}

The present study was supported by the Korea Health Technology R\&D Project through the Korea Health Industry Development Institute, funded by the Ministry of Health \& Welfare, Republic of Korea (grant no. HI18C2383) and the National Research Foundation of Korea, which is funded by the Ministry of Education (grant no. 2018M3A9H3022412).

\section{Availability of data and materials}

The datasets used and/or analyzed during the present study are available from the corresponding author on reasonable request.

\section{Authors' contributions}

SJO and SR were responsible for the study design. APC and NP performed the main experiments related to apoptosis and oncogenic based assays, and drafted the manuscript.
NRK performed cell viability assays and performed statistical analysis. All authors read and approved the final manuscript.

\section{Ethics approval and consent to participate}

Not applicable.

\section{Patient consent for publication}

Not applicable.

\section{Competing interests}

The authors declare that they have no competing interests.

\section{References}

1. Bray F, Ferlay J, Soerjomataram I, Siegel RL, Torre LA and Jemal A: Global cancer statistics 2018: GLOBOCAN estimates of incidence and mortality worldwide for 36 cancers in 185 countries. CA Cancer J Clin 68: 394-424, 2018.

2. Burd EM: Human papillomavirus and cervical cancer. Clin Microbiol Rev 16: 1-17, 2003.

3. Soto D, Song C and McLaughlin-Drubin ME: Epigenetic alterations in human papillomavirus-associated cancers. Viruses 9: 248-265, 2017.

4. Willms A, Schittek H, Rahn S, Sosna J, Mert U, Adam D and Trauzold A: Impact of p53 status on TRAIL-mediated apoptotic and non-apoptotic signaling in cancer cells. PLoS One 14: e0214847, 2019.

5. Wang S and El-Deiry WS: TRAIL and apoptosis induction by TNF-family death receptors. Oncogene 22: 8628-8633, 2003.

6. Zhang L and Fang B: Mechanisms of resistance to TRAIL-induced apoptosis in cancer. Cancer Gene Ther 12: 228-2237, 2005.

7. Pitti RM, Marsters SA, Ruppert S, Donahue CJ, Moore A and Ashkenazi A: Induction of apoptosis by Apo-2 ligand, a new member of the tumor necrosis factor cytokine family. J Biol Chem 271: 12687-12690, 1996.

8. Poondla N, Chandrasekaran AP, Heese K, Kim KS and Ramakrishna S: CRISPR-mediated upregulation of DR5 and downregulation of cFLIP synergistically sensitize HeLa cells to TRAIL-mediated apoptosis. Biochem Biophys Res Commun 512: 60-65, 2019.

9. Seo OW, Kim JH, Lee KS, Lee KS, Kim JH, Won MH, Ha KS, Kwon YG and Kim YM: Kurarinone promotes TRAIL-induced apoptosis by inhibiting NF- $\kappa \mathrm{B}-$ dependent cFLIP expression in HeLa cells. Exp Mol Med 44: 653-664, 2012.

10. Yang A, Wilson NS and Ashkenazi A: Proapoptotic DR4 and DR5 signaling in cancer cells: Toward clinical translation. Curr Opin Cell Biol 22: 837-844, 2010.

11. Russo M, Mupo A, Spagnuolo C and Russo GL: Exploring death receptor pathways as selective targets in cancer therapy. Biochem Pharmacol 80: 674-682, 2010.

12. Malhi $\mathrm{H}$ and Gores GJ: TRAIL resistance results in cancer progression: A TRAIL to perdition? Oncogene 25: 7333-7335, 2006.

13. Mobahat M, Narendran A and Riabowol K: Survivin as a preferential target for cancer therapy. Int J Mol Sci 15: 2494-2516, 2014.

14. Fukuda S and Pelus LM: Survivin, a cancer target with an emerging role in normal adult tissues. Mol Cancer Ther 5: 1087-1098, 2006.

15. Shin S, Sung BJ, Cho YS, Kim HJ, Ha NC, Hwang JI, Chung CW, Jung JK and Oh BH: An Anti-apoptotic protein human survivin is a direct inhibitor of caspase-3 and -7. Biochemistry 40 : 1117-1123, 2001.

16. Lv YG, Yu F, Yao Q, Chen JH and Wang L: The role of survivin in diagnosis, prognosis and treatment of breast cancer. J Thorac Dis 2: 100-110, 2010.

17. Cao XQ, Lu HS, Zhang L, Chen LL and Gan MF: MEKK3 and survivin expression in cervical cancer: Association with clinicopathological factors and prognosis. Asian Pacific J Cancer Prev 15: 5271-5276, 2014. 
18. Falleni M, Pellegrini C, Marchetti A, Oprandi B, Buttitta F, Barassi F, Santambrogio L, Coggi G and Bosari S: Survivin gene expression in early-stage non-small cell lung cancer. J Pathol 200: 620-626, 2003.

19. Trieb K, Lehner R, Stulnig T, Sulzbacher I and Shroyer KR: Survivin expression in human osteosarcoma is a marker for survival. Eur J Surg Oncol 29: 379-82, 2003.

20. Park SH, Park SJ, Kim JO, Shin J-H, Kim ES, Jo YK, Kim JS, Park SJ, Jin DH, Hwang JJ, et al: Down-regulation of survivin by nemadipine-a sensitizes cancer cells to TRAIL-induced apoptosis. Biomol Ther (Seoul) 21: 29-34, 2013.

21. Hwang JS, Lee HC, Oh SC, Lee DH and Kwon KH: Shogaol overcomes TRAIL resistance in colon cancer cells via inhibiting of survivin. Tumor Biol 36: 8819-8829, 2015.

22. Véquaud E, Séveno C, Loussouarn D, Engelhart L, Campone M, Juin $\mathrm{P}$ and Barillé-Nion S: YM155 potently triggers cell death in breast cancer cells through an autophagy-NF-kB network. Oncotarget 6: 13476-13486, 2015.

23. Cheng XJ,Lin JC, Ding YF,Zhu L, Ye J and Tu SP: Survivin inhibitor YM155 suppresses gastric cancer xenograft growth in mice without affecting normal tissues. Oncotarget 7: 7096-7109, 2016.

24. Zhang C, Cao x, Gei Y, Wang Y, Liu G, Cheng G and Liu Q: Silencing of survivin by YM155 induces apoptosis and growth arrest in hepatocellular carcinoma cells. Oncol Lett 10: 1627-1631, 2015.

25. Zhao X, Puszyk WM, Lu Z, Ostrov DA, George TJ, Robertson KD and Liu C: Small molecule inhibitor YM155-mediated activation of death receptor 5 is crucial for chemotherapy-induced apoptosis in pancreatic carcinoma. Mol Cancer Ther 14: 80-89, 2015.

26. Jane EP, Premkumar DR, Sutera PA, Cavaleri JM and Pollack IF: Survivin inhibitor YM155 induces mitochondrial dysfunction, autophagy, DNA damage and apoptosis in Bcl-xL silenced glioma cell lines. Mol Carcinog 56: 1251-1265, 2017.

27. Sim MY, Huynh H, Go ML and Yuen JSP: Action of YM155 on clear cell renal cell carcinoma does not depend on survivin expression levels. PLoS One 12: e0178168, 2017.

28. Zhao N, Mao Y, Han G, Ju Q, Zhou L, Liu F, Xu Y and Zhao X: YM155, a survivin suppressant, triggers PARP-dependent cell death (parthanatos) and inhibits esophageal squamous-cell carcinoma xenografts in mice. Oncotarget 6: 18445-18459, 2015

29. Li WL, Lee MR and Cho MY: The small molecule survivin inhibitor YM155 may be an effective treatment modality for colon cancer through increasing apoptosis. Biochem Biophys Res Commun 471: 309-314, 2016

30. Feng W, Yoshida A and Ueda T: YM155 induces caspase- 8 dependent apoptosis through downregulation of survivin and Mcl-1 in human leukemia cells. Biochem Biophys Res Commun 435 52-57, 2013.

31. Woo SM, Min K, Seo BR and Kwon TK: YM155 sensitizes TRAIL-induced apoptosis through cathepsin S-dependent down-regulation of Mcl-1 and NF- $\kappa \mathrm{B}$-mediated down-regulation of c-FLIP expression in human renal carcinoma Caki cells. Oncotarget 7: 61520-61532,2016.

32. Azuhata T, Scott D, Griffith TS, Miller M and Sandler AD Survivin inhibits apoptosis induced by TRAIL, and the ratio between survivin and TRAIL receptors is predictive of recurrent disease in neuroblastoma. J Pediatr Surg 41: 1431-1440, 2006.

33. Livak KJ and Schmittgen TD: Analysis of relative gene expression data using real-time quantitative PCR and the 2(-Delta Delta C(T)) method. Methods 25: 402-408, 2001

34. Latifi-Pupovci H, Kuçi Z, Wehner S, Bönig H, Lieberz R, Klingebiel T, Bader P and Kuçi S: In vitro migration and proliferation ('wound healing') potential of mesenchymal stromal cells generated from human CD271+ bone marrow mononuclear cells. J Transl Med 13: 315-323, 2015.

35. Kuang AA, Diehl GE, Zhang $\mathbf{J}$ and Winoto A: FADD is required for DR4- and DR5-mediated apoptosis. J Biol Chem 275: 25065-25068, 2000.

36. Ponder KG and Boise LH: The prodomain of caspase- 3 regulates its own removal and caspase activation. Cell Death Discov 5: 56 , 2019.

37. Salvesen GS: Caspases: Opening the boxes and interpreting the arrows. Cell Death Differ 9: 3-5, 2002.

38. Siegel RL, Miller KD and Jemal A: Cancer statistics, 2020. CA Cancer J Clin 70: 7-30, 2020

39. Maduro JH, de Vries EGE, Meersma GJ, Hougardy BMT, van der Zee AGJ and de Jong S: Targeting pro-apoptotic TRAIL receptors sensitizes HeLa cervical cancer cells to irradiation-induced apoptosis. Int J Radiat Oncol Biol Phys 72: 543-552, 2008
40. Nakahara T, Kita A, Yamanaka K, Mori M, Amino N, Takeuchi M, Tominaga F, Hatakeyama S, Kinoyama I, Matsuhisa A, et al: YM155, a novel small-molecule survivin suppressant, induces regression of established human hormone-refractory prostate tumor xenografts. Cancer Res 67: 8014-8021, 2007.

41. Rauch A, Hennig D, Schäfer C, Wirth M, Marx C, Heinzel T, Schneider G and Krämer OH: Survivin and YM155: How faithful is the liaison? Biochim Biophys Acta 1845: 202-220, 2014.

42. Kelly RJ, Thomas A, Rajan A, Chun G, Lopez-Chavez A, Szabo E, Spencer S, Carter CA, Guha U, Khozin S, et al: A phase I/II study of sepantronium bromide (YM155, survivin suppressor) with paclitaxel and carboplatin in patients with advanced non-small-cell lung cancer. Ann Oncol 24: 2601-2606, 2013.

43. Giaccone G, Zatloukal P, Roubec J, Floor K, Musil J, Kuta M, van Klaveren RJ, Chaudhary R, Gunther A and Shamsili S: Multicenter phase II trial of YM155, a small-molecule suppressor of survivin, in patients with advanced, refractory, non-small-cell lung cancer. J Clin Oncol 27: 4481-4486, 2009.

44. Pennati M, Sbarra S, Cesare MD, Lopergolo A, Locatelli SL, Campi E, Daidone MG, Carlo-Stella C, Gianni AM and Zaffaroni N: YM155 sensitizes triple-negative breast cancer to membrane-bound TRAIL through p38 MAPK- and CHOP-mediated DR5 upregulation. Int J Cancer 136: 299-309, 2015.

45. Iwasa T, Okamoto I, Suzuki M, Nakahara T, Satoh T, Fukuoka M, Ono K and Nakagawa K: Radiosensitizing effect of YM155, a novel Small-molecule survivin suppressant, in Non-small cell lung cancer cell lines. Clin Cancer Res 14: 6496-6504, 2008.

46. Hong M, Ren MQ, Silva J, Paul A, Wilson WD, Schroeder C, Weinberger P, Janik J and Hao Z: YM155 inhibits topoisomerase function. Anticancer Drugs 28: 142-152, 2017.

47. Nakamura H, Taguchi A, Kawana K, Baba S, Kawata A, Yoshida M, Fujimoto A, Ogishima J, Sato M, Inoue T, et al: Therapeutic significance of targeting survivin in cervical cancer and possibility of combination therapy with TRAIL. Oncotarget 9: 13451-13461, 2018.

48. Ryu AH, Eckalbar WL, Kreimer A, Yosef N and Ahituv N: Use antibiotics in cell culture with caution: Genome-wide identification of antibiotic-induced changes in gene expression and regulation. Sci Rep 7: 7533, 2017.

49. Winter GE, Radic B, Mayor-Ruiz C, Blomen VA, Trefzer C, Kandasamy RK, Huber KVM, Gridling M, Chen D, Klampfl T, et al: The solute carrier SLC35F2 enables YM155-mediated DNA damage toxicity. Nat Chem Biol 10: 768-773, 2014.

50. Griffith T, Stokes B, Kucaba T, Earel J Jr, van Oosten R, Brincks E and Norian L: TRAIL Gene therapy: From preclinical development to clinical application. Curr Gene Ther 9: 9-19, 2009.

51. Yamanaka K, Nakahara T, Yamauchi T, Kita A, Takeuchi M, Kiyonaga F, Kaneko N and Sasamata M: Antitumor activity of YM155, a selective Small-molecule survivin suppressant, alone and in combination with docetaxel in human malignant melanoma models. Clin Cancer Res 17: 5423-5431, 2011.

52. Wiley SR, Schooley K, Smolak PJ, Din WS, Huang CP, Nicholl JK, Sutherland GR, Smith TD, Rauch C, Smith CA, et al: Identification and characterization of a new member of the TNF family that induces apoptosis. Immunity 3: 673-682, 1995.

53. Kim K, Fisher MJ, Xu SQ and El-Deiry WS: Molecular determinants of response to TRAIL in killing of normal and cancer cells. Clin Cancer Res 6: 335-346, 2000.

54. Kang Z, Sun SY and Cao L: Activating Death receptor DR5 as a therapeutic strategy for rhabdomyosarcoma. ISRN Oncol 2012: 395952, 2012

55. Day TW, Najafi F, Wu CH and Safa AR: Cellular FLICE-like inhibitory protein (c-FLIP): A novel target for Taxol-induced apoptosis. Biochem Pharmacol 71: 1551-1561, 2006.

56. Zong H, Yin B, Chen J, Ma B, Cai D and He X: Over-Expression of c-FLIP confers the resistance to TRAIL-induced apoptosis on gallbladder carcinoma. Tohoku J Exp Med 217: 203-208, 2009.

57. Surget S, Chiron D, Gomez-Bougie P, Descamps G, Ménoret E, Bataille R, Moreau P, Gouill SL, Amiot M and Pellat-Deceunynck C: Cell death via DR5, but not DR4, is regulated by p53 in myeloma cells. Cancer Res 72: 4562-4573, 2012.

58. Chen S, Fu L, Raja SM, Yue P, Khuri FR and Sun SY: Dissecting the roles of DR4, DR5 and c-FLIP in the regulation of Geranylgeranyltransferase I inhibition-mediated augmentation of TRAIL-induced apoptosis. Mol Cancer 9: 23, 2010. 
59. Refaat A, Abd-Rabou A and Reda A: TRAIL combinations: The new 'trail' for cancer therapy (Review). Oncol Lett 7: 1327-1332, 2014.

60. Gasparian ME, Chernyak BV, Dolgikh DA, Yagolovich AV, Popova EN, Sycheva AM, Moshkovskii SA and Kirpichnikov MP: Generation of new TRAIL mutants DR5-A and DR5-B with improved selectivity to death receptor 5. Apoptosis 14: 778-787, 2009.

61. Kischkel FC, Lawrence DA, Chuntharapai A, Schow P, Kim KJ and Ashkenazi A: Apo2L/TRAIL-dependent recruitment of endogenous FADD and caspase- 8 to death receptors 4 and 5 . Immunity 12: 611-620, 2000.

62. Thomas LR, Henson A, Reed JC, Salsbury FR and Thorburn A: Direct binding of Fas-associated death domain (FADD) to the tumor necrosis Factor-related Apoptosis-inducing ligand receptor DR5 is regulated by the death effector domain of FADD. J Biol Chem 279: 32780-32785, 2004.
63. Wang W, Wang S, Song X, Sima N, Xu X, Luo A, Chen G, Deng D, Xu Q, Meng L, et al: The relationship between c-FLIP expression and human papillomavirus E2 gene disruption in cervical carcinogenesis. Gynecol Oncol 105: 571-577, 2007.

64. Hu Z and Ma D: The precision prevention and therapy of HPV-related cervical cancer: New concepts and clinical implications. Cancer Med 7: 5217-5236, 2018.

This work is licensed under a Creative Commons Attribution-NonCommercial-NoDerivatives 4.0 International (CC BY-NC-ND 4.0) License. 